\title{
A case of moderate depression with somatic symptoms and incidental finding of retrocerebellar arachnoid cyst
}

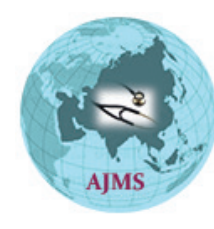

\author{
Sumit Mukherjee ${ }^{1}$, Aparupa Bhattacharya ${ }^{2}$ \\ ${ }^{1}$ Senior Resident, Department of Psychiatry, Calcutta Pavlov Hospital, ${ }^{2}$ Clinical Psychologist, District Mental Health \\ Programme (North 24 Parganas), Kolkata, West Bengal, India
}

Arachnoid cysts are benign space-occupying brain lesions that contain cerebrospinal fluid which is mostly congenital in origin. Cases are mostly detected incidentally on neuro-imaging and neuropsychiatric manifestations are less common and under-recognized. Arachnoid cyst sometimes may be associated with seizure, headache, cranial nerve deficits, hydrocephalus, etc. A 23-year-old married female from rural India presented with headache, insomnia, low mood, lethargy, persisting for the past 6 months without any obvious stress factors. She also informed that she had few episodes of unresponsiveness without any features such as tongue biting, confusion, injury, or involuntary micturition and defecation. Her EEG report was within normal limit and MRI report confirmed the presence of Retro-cerebellar Arachnoid cyst in and around midline. Detail neurological and ophthalmological examination was done and findings were within normal limits. She was treated with Amitriptyline, Pregabalin, and Paracetamol. Psychotherapy was initiated for adequate management of her depressive symptoms and responded well. It can be emphasized that patients who are reporting with symptoms such as headache a detail evaluation should be done to find out organic etiology. Depressive and cognitive symptoms and its association with arachnoid cyst may depend upon the location of the lesion and further research is required to establish its causal relationship.

Key words: Arachnoid cyst; Headache; Insomnia, Low mood; Psychotherapy
Access this article online

Website:

http://nepjol.info/index.php/AJMS DOI: 10.3126/ajms.v12i11.38941

E-ISSN: 2091-0576

P-ISSN: 2467-9100

Copyright (c) 2021 Asian Journal of Medical Sciences

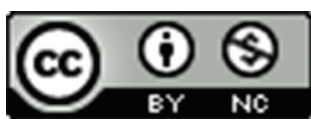

This work is licensed under a Creative Commons Attribution-NonCommercial 4.0 International License.

\section{INTRODUCTION}

Arachnoid cysts are benign space-occupying intracranial lesions that contain cerebrospinal fluid and mostly of congenital origin. It is caused by failed fusion of the arachnoid membrane early in fetal development. ${ }^{1}$ Arachnoid cysts are the commonest intracranial cyst, accounting for around 1\% of all intracranial spaceoccupying lesions. ${ }^{2}$ Their clinical manifestations vary and are often nonspecific. ${ }^{3}$ Enlargement of arachnoid cysts can be caused by fluid secretion from ependymal cells and fluid ingress secondary to an osmotic gradient resulting in trapping of fluid by a ball/valve mechanism and subsequently strenuous venous pulsation produced during Valsalva maneuvers. ${ }^{4}$ Arachnoid cysts are more common in males in comparison to females with a prevalence ratio of $3: 1 .^{5} \mathrm{~A}$ few cases with associated psychiatric symptoms have been reported. Such type of cases are mostly detected incidentally on neuroimaging whereas neuropsychiatric manifestations are under-recognized. Arachnoid cyst occasionally may be associated with episodes of seizure, headache, and cranial nerve deficits.

\section{CASE PRESENTATION}

A 23-years-old married Muslim female from rural India presented with headache, insomnia, low mood, lethargy, persisting for the past 6 months without any obvious stress factors. She also informed that she had few episodes of unresponsiveness without any features such as tongue biting, confusion, injury, or involuntary micturition and defecation. She reported early morning awakening in the 

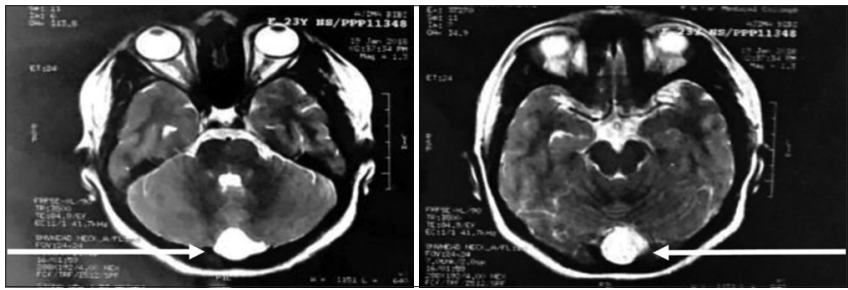

Figure 1: Pointed arrow indicates the hyperdense area suggestive of Retro-cerebellar Arachnoid cyst in MRI Brain

past few months. Her EEG report was within normal limit and MRI report confirmed the presence of Retrocerebellar Arachnoid cyst in and around midline (Figure 1). Neurological and relevant ophthalmological examinations were done and findings were within normal limits. Hormonal assay and other biochemical investigations were also within normal limit. On mental status examination, patient was having speech with decreased tone, volume, and tempo with increased reaction time. She reported that she was not feeling well in most of the time of the day and not getting interest in performing regular household activities. Her affect was depressed with inadequate eye contact. She had no obvious thought disturbance and there was no perceptual anomaly. Her insight and judgment were intact during mental status examination. She was treated with low dosage of Amitriptyline, Pregabalin initially and at subsequent stages, the dosage of Amitriptyline had been increased up to $75 \mathrm{mg} /$ day. Cognitive behavior therapy was initiated for adequate management of her depressive symptoms and responded well. She was advised for regular follow-up at Neuro-surgery clinic for management of the cyst.

\section{DISCUSSION}

In psychiatric clinical practice, we daily encounter patients who show psychotic symptoms, depressive symptoms being either recurrent or as first episodes of the disease. In case of hospitalization or in out-patient department clinical evaluation and psychological tests are always done along with a series of other diagnostic procedures such as routine blood investigations, EEG, and firstly CT scan of brain and MRI if necessary. In this case, as there was no history of any head trauma this retro-cerebellar arachnoid cyst may be of congenital origin. The cyst may have increased in size over the time and developed symptoms like headache and discomfort. It can also be stated that due to this long-standing headache the patient was not been able to perform her regular household activities and subsequently developed the features of depression-like low mood, lethargy, disturbed sleep, and other vague somatic symptoms as well as repeated episodes of unresponsiveness which were similar to conversion symptoms. All these symptoms had improved after adding antidepressant and Pregabalin along with psychotherapy. In this case maintenance of liaison with Neuro-medicine department and regular follow-up in their setup had helped to achieve the best possible result.

\section{CONCLUSION}

It can be emphasized that patients who are reporting with symptoms such as headache, a detail neurological evaluation and neuroimaging should be done to find out organic aetiology. Depressive and cognitive symptoms and its association with Arachnoid cyst may depend upon the location of the lesion and further research is necessary to establish the causal relationship.

\section{REFERENCES}

1. Hayashi T, Shirouzu T, Miyagi J, Kawai K, Anegawa S and Kuramoto S. Temporal arachnoid cyst. Kurume Med J. 1979;26(1):57-62.

https://doi.org/10.2739/kurumemedj.26.57

2. Gosalakkal JA. Intracranial arachnoid cysts in children: A review of pathogenesis, clinical features, and management. Pediatr Neurol. 2002;26(2):93-98.

https://doi.org/10.1016/s0887-8994(01)00329-0

3. Cincu R, Agrawal A and Eiras J. Intracranial arachnoid cysts: Current concepts and treatment alternatives. Clin Neurol Neurosurg. 2007;109(10):837-843.

https://doi.org/10.1016/j.clineuro.2007.07.013

4. Williams B and Guthkelch AN. Why do central arachnoid pouches expand? J Neurol Neurosurg Psychiatry. 1974;37(10):1085-1092. https://doi.org/10.1136/jnnp.37.10.1085

5. Wester K. Gender distribution and sidedness of middle fossa arachnoid cysts: A review of cases diagnosed with computed imaging. Neurosurgery. 1992;31(5):940-944.

https://doi.org/10.1097/00006123-199211000-00018

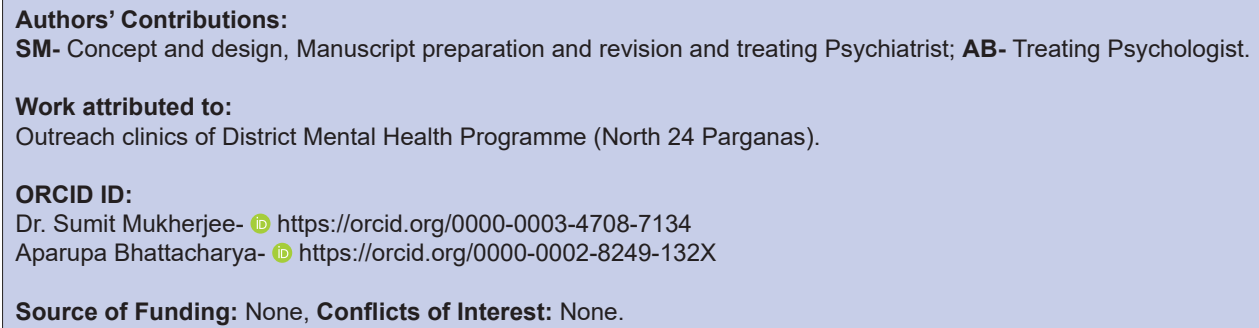

